\title{
Endometriosis and assisted reproduction
}

Milena Kralickova ${ }^{1,2,3}$ and Vaclav Vetvicka ${ }^{4 *}$

*Correspondence: Vaclav.vetvicka@louisville.edu

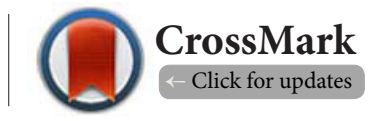

\begin{abstract}
'Department of Histology and Embryology, Faculty of Medicine, Charles University, Karlovarska 48, Plzen, Czech Republic, Europe. ${ }^{2}$ Department of Obstetrics and Gynecology, University Hospital, Faculty of Medicine, Charles University, Alej Svobody 80, Plzen, Czech Republic, Europe.

${ }^{3}$ Biomedical Centre, Faculty of Medicine in Plzen, Charles University, Plzen, Czech Republic, Europe.

${ }^{4}$ University of Louisville, Department of Pathology, 511 S. Floyd, Louisville, KY 40202, USA.
\end{abstract}

\begin{abstract}
Endometriosis is a physiological state in which endometrial tissue is present outside the uterine cavity. The prevalence rate is estimated to be between 10 to $15 \%$ in women in reproductive age and is often associated with infertility. Despite extensive studies, no mechanisms of the endometriosis-connected infertility have been found. Only two types of treatment are currently recommended-either surgery or in vitro fertilization. However, the success of either option is still rather controversial.
\end{abstract}

Keywords: Endometriosis, infertility, IVF, fertility

\section{Introduction}

Endometriosis usually defined as the presence of endometriallike tissue outside the uterus, is a condition affecting about $10 \%$ of the population of women in reproductive age. Whereas the effects on overall health conditions and life comfort are significant, endometriosis also affects women's fertility. In infertile women, the occurrence of endometriosis can reach up to $40 \%$ (compared to $0.5-5 \%$ in fertile women). Therefore, women with endometriosis often require artificial reproductive techniques. The association of endometriosis and infertility seems to be clear. However, the mechanisms behind this association and even the question of whether women with endometriosis have adverse pregnancies remain unsolved. However, in low grade endometriosis, the direct relationship between and infertility is less clear [1]. For suggested mechanisms, see an excellent review [2].

Despite progress, the options for treating these problems are still limited. In addition, optimal practice for treating moderate to severe endometriosis-related infertility is widely debated without any consensus reached. As hormone treatment has no effects, the only available choices remain surgery or assisted reproductive technologies, such as IVF.

\section{Review}

Ovarian responsiveness

In case of severe endometriosis, there is significant risk for ovarian tissue damage, particularly after repeated surgeries and/or in the presence of bilateral endometriomas. There is limited evidence to suggest improvements in fertility associated ovarian suppression prior to non-IVF treatment for infertility. An important point is the severity of endometriosis-association between mild to severe forms and infertility has been attributed to impaired ovarian release of oocytes, inhibited tubal ovum capture and diminished gamete transport [3].

A systematic review and meta-analysis of nine studies including 1039 cases showed that ovarian endometrioma was clearly associated with fewer oocytes and metaphase II oocytes retrieved, and fewer total formed embryos. Overall numbers of pregnancies and live births were not affected [4]. It seems that ovaries with endometriomas have similar response to stimulation to normal healthy ovaries from the same individual, suggesting that assisted reproduction may be more beneficial than laparoscopic ovarian surgery. Several mechanisms were suggested, including altered folliculogenesis, different conditions in the peritoneal fluid or anatomical dysfunction, but none of them were fully confirmed. All of these changes may result in poorer quality of oocytes with reduced fertilization rates. In addition, numerous molecular, histological and morphological alterations found in endometriotic cysts provide evidences that endometriosis diminishes ovarian function [5].

With known effects of endometriosis on ovarian functions, recent advances in fertility preservation techniques such as 
Kralickova et al., Pathology Discovery 2017,

oocytes and ovarian tissue freezing become an interesting alternative. Originally suggested as a standard of care for patients with a risk of acute premature ovarian failure as a result of cancer treatment, this option is also now considered in patients with endometriosis [6]. The major fertility preservation techniques involve ovarian sparing surgery, embryo and/ or egg freezing and ovarian tissue cryopreservation. However, more data will be necessary to fully recommend these options in women suffering from endometriosis-related infertility.

\section{Direct IVF}

IVF is an effective tool to overcome endometriosis-based infertility, particularly when other options fail. In theory, IVF should preempt the deleterious effects of endometriosis, as it is not dependent on the correct function of the fallopian tubes. In addition, compromised pelvic anatomy and the potentially hostile peritoneal environment are bypassed.

The question does endometriosis affect IVF results is still rather controversial. In mild cases of endometriosis, lower success rates were sometimes reported [7]. Large meta-analysis reported significantly lower success of IVF [8,9]. On the other hand, an analysis of 616 patients [10] and a retrospective case-controlled study of 571 patients found no significant differences [11]. In addition, no additional risk of miscarriage was found in patients with endometriosis fertilized via IVF [12]. A study of 787 women showed that although women with endometriosis often have a poor ovarian reserve, the chance of conceiving by IVF/ICSI is similar to healthy populations [13].

Similarly, a retrospective study evaluating ovarian stimulation outcomes in women with endometriosis undergoing IVF showed that simple presence of endometriosis does not affect the outcome of the exogenous gonadotropin stimulation [14]. Direct comparison of healthy women with women with stage I/II endometriosis showed higher requirements for gonadotropin, lower percentage of high-quality embryos and low pregnancy rates in groups with endometriosis suggesting negative effects on IVF outcome, probably due to lower embryo quality [15]. In addition, a systematic review and meta-analysis showed that women with stage III/IV endometriosis had poor implantation and clinical pregnancy rates after IVF treatment [9]. Similar studies showed that excision of endometriosis in patients scheduled for IVF does not improve the chance for successful pregnancy [16]. On the other hand, retrospective cohort study found no differences in IVF/ICSI pregnancy outcomes [17].

A study assessed oxidative stress and trace elements in the oocytes environment in endometriosis and the possible effects on IVF showed increased ROS and NO in endometriosis and increased levels of ROS, NO, LPS, cadmium and lead in women who did not become pregnant [18]. These results suggest that extracellular conditions in endometriosis might have a significant impact on success of IVF. A study evaluating risk of miscarriage in women achieving singleton pregnancies via IVF showed no increase in women with endometriosis [12].
Administration of a prolonged course of $\mathrm{GnRHa}$ or other suppressive agents seemed to improve IVF outcome, but it is currently unknown how to pick the optimal candidate for this type of therapy [19]. So far, we are lacking a diagnostic marker which would specifically identify those who would benefit from this pretreatment [20].

Some studies suggested that in isolated cases the conditions might worsen during preparation for IVF [21]. However, several recent detailed studies showed that assisted reproductive technology has no adverse effects on quality of life of infertile endometriotic patients [19,22].

\section{Role of surgery}

Surgical solution aims on removing macroscopic endometriotic implants and to restore normal anatomy of the pelvis. The question whether surgery can improve fertility outcome in patients with endometriosis is still unsolved and a matter of intensive debate. Even current guidelines of the European Society of Human Reproduction and Embryology are inconclusive [23]. A summary of recent observations is given in an excellent review [24].

Despite the fact that this treatment is quite common, some questioned whether repeated surgeries followed by IVF did not participate in disease progression as severe ovarian damage and extensive follicle loss have been reported after cystectomy for endometriomas [25]. However, a retrospective case-control study proved that IVF treatment does not lead to an accelerated progression [26]. However, lower spontaneous pregnancy rates after secondary surgery exist [2].

In general, surgical excision or ablation of endometriosis is recommended for women with minimal or mild endometriosis, but lately, the same treatment is even recommended for patients with several endometriosis. However, in patients who failed to spontaneously conceive after surgery, assisted reproduction is more effective than repeat surgery [27]. The most probable reason for the failure is a decrease in ovarian reserve.

Recent studies revealed that women with severe endometriosis and repeated IVF failures might benefit from extensive laparoscopic surgery including extensive excision of endometrial lesions and even urinary and bowel resection [28]. A systematic review and meta-analysis of subfertile women with endometriosis undergoing IVF found similar reproductive outcomes as found in groups of healthy women. Surgical treatment did not alter the outcome of IVF. The authors concluded that individualization of care for these women might help optimize their IVF results [29].

\section{Conclusion}

The mechanisms for endometriosis-related infertility are not fully understood. The fact that they probably are different in different stages of endometriosis seems to further confuse the problem. The options for treating infertile women with endometriosis include surgery of assisted reproduction. The 
Kralickova et al., Pathology Discovery 2017,

outcome is based not only on the stage of endometriosis, but also on age of the patients. In young women with mild disease or small endometriomas, surgery has beneficial effects. In older women, surgery has no clear benefits (for review see [30]). It is important to keep in mind that study designs, inclusion criteria and significant variations in types of treatment exist, making comparing outcomes difficult.

Current data showed that medical treatment of endometriosis will not improve spontaneous pregnancies. It is similarly clear that there are significantly more infertile women than women with endometriosis, but questions such as "is surgery helping" or "does endometriosis affects results of IVF" remain unclear and require more studies.

\section{Competing interests}

The authors declare that they have no competing interests.

Authors' contributions

\begin{tabular}{|l|c|c|}
\hline Authors' contributions & MK & VV \\
\hline Research concept and design & -- & -- \\
\hline Collection and/or assembly of data & $\checkmark$ & $\checkmark$ \\
\hline Data analysis and interpretation & -- & -- \\
\hline Writing the article & $\checkmark$ & $\checkmark$ \\
\hline Critical revision of the article & $\checkmark$ & $\checkmark$ \\
\hline Final approval of article & $\checkmark$ & $\checkmark$ \\
\hline Statistical analysis & -- & -- \\
\hline
\end{tabular}

\section{Acknowledgement}

We would like to thank Ms. Mary Williams for final editing.

Publication history

EIC: Markus H. Frank, Harvard Medical School, USA.

Received: 13-Mar-2017 Accepted: 14-Apr-2017

Published: 25-Apr-2017

\section{References}

1. Berube S, Marcoux S, Langevin M and Maheux R. Fecundity of infertile women with minimal or mild endometriosis and women with unexplained infertility. The Canadian Collaborative Group on Endometriosis. Fertil Steril. 1998; 69:1034-41. | Article | PubMed

2. Leung AS and Dahan $\mathrm{MH}$. The benefits of other treatments than in vitro fertilization to aid conception in minimal and mild endometriosis. Minerva Ginecol. 2016; 68:675-86. I Article I PubMed

3. Pfeifer S, Fritz M, Goldberg J, McClure R, Lobo R, Thomas M, Widra E, Schattman G, Licht M, Collins J, Cedars M, Racowsky C, Vernon M, Davis O, Barnhart K, Gracia C, Catherino W, Rebar R and Barbera A.L. Endometriosis and infertility: a committee option. Fertil Steril. 2012; 98:591-598.

4. Yang C, Geng Y, Li Y, Chen C and Gao Y. Impact of ovarian endometrioma on ovarian responsiveness and IVF: a systematic review and metaanalysis. Reprod Biomed Online. 2015; 31:9-19. | Article | PubMed

5. Sanchez AM, Vigano $P$, Somigliana $E$, Panina-Bordignon $P$, Vercellini $P$ and Candiani M. The distinguishing cellular and molecular features of the endometriotic ovarian cyst: from pathophysiology to the potential endometrioma-mediated damage to the ovary. Hum Reprod Update. 2014; 20:217-30. | Article I PubMed

6. Carrillo L, Seidman DS, Cittadini E and Meirow D. The role of fertility preservation in patients with endometriosis. J Assist Reprod Genet. 2016; 33:317-23. | Article | PubMed Abstract | PubMed FullText
7. Arici A, Oral E, Bukulmez O, Duleba A, Olive DL and Jones EE. The effect of endometriosis on implantation: results from the Yale University in vitro fertilization and embryo transfer program. Fertil Steril. 1996; 65:603-7. | Article | PubMed

8. Barnhart K, Dunsmoor-Su R and Coutifaris C. Effect of endometriosis on in vitro fertilization. Fertil Steril. 2002; 77:1148-55. | Article | PubMed

9. Harb HM, Gallos ID, Chu J, Harb M and Coomarasamy A. The effect of endometriosis on in vitro fertilisation outcome: a systematic review and meta-analysis. BJOG. 2013; 120:1308-20. | Article | PubMed

10. Polat M, Boynukalin FK, Yarali I, Esinler I and Yarali $\mathrm{H}$. Endometriosis is not associated with inferior pregnancy rates in in vitro fertilization: an analysis of 616 patients. Gynecol Obstet Invest. 2014; 78:59-64. I Article I PubMed

11. Polat $\mathrm{M}$, Yarali I, Boynukalin $\mathrm{K}$ and Yarali $\mathrm{H}$. In vitro fertilization for endometriosis-associated infertility. Womens Health (Lond). 2015; 11:633-41. | Article | PubMed

12. Leonardi M, Papaleo E, Reschini M, Pagliardini L, Benaglia L, Candotti G, Vigano P, Quaranta L, Munaretto M, Candiani M, Vercellini P and Somigliana $\mathrm{E}$. Risk of miscarriage in women with endometriosis: insights from in vitro fertilization cycles. Fertil Steril. 2016; 106:386-392 e3. | Article | PubMed

13. Coelho Neto MA, Martins Wde P, Luz CM, Jianini BT, Ferriani RA and Navarro PA. Endometriosis, Ovarian Reserve and Live Birth Rate Following In Vitro Fertilization/Intracytoplasmic Sperm Injection. Rev Bras Ginecol Obstet. 2016; 38:218-24. I Article I PubMed

14. Luca A, Nemescu D, Butnaru M, Butnariu A and Onofriescu M. Ovarian stimulation outcome in infertile women with endometriosis undergoing IVF. Ginekol Pol. 2016; 87:37-41. | Article | PubMed

15. Mekaru K, Yagi C, Asato K, Masamoto H, Sakumoto K and Aoki Y. Effects of early endometriosis on IVF-ET outcomes. Front Biosci (Elite Ed). 2013; 5:720-4. | Article | PubMed

16. Demirol A, Guven S, Baykal C and Gurgan T. Effect of endometrioma cystectomy on IVF outcome: a prospective randomized study. Reprod Biomed Online. 2006; 12:639-43. | Article | PubMed

17. Dong $X$, Liao $X$, Wang $R$ and Zhang $H$. The impact of endometriosis on IVF/ICSI outcomes. Int J Clin Exp Pathol. 2013; 6:1911-8. | PubMed Abstract | PubMed FullText

18. Singh AK, Chattopadhyay R, Chakravarty B and Chaudhury K. Markers of oxidative stress in follicular fluid of women with endometriosis and tubal infertility undergoing IVF. Reprod Toxicol. 2013; 42:116-24. I Article I PubMed

19. Surrey ES. Endometriosis and assisted reproductive technologies: maximizing outcomes. Semin Reprod Med. 2013; 31:154-63. | Article | PubMed

20. Surrey ES. Endometriosis-Related Infertility: The Role of the Assisted Reproductive Technologies. Biomed Res Int. 2015; 2015:482959. | Article | PubMed Abstract | PubMed FullText

21. Anaf V, El Nakadi I, Simon P, Englert Y, Peny MO, Fayt I and Noel JC. Sigmoid endometriosis and ovarian stimulation. Hum Reprod. 2000; 15:790-4. | Article | PubMed

22. Santulli P, Bourdon M, Presse M, Gayet V, Marcellin L, Prunet C, de Ziegler D and Chapron C. Endometriosis-related infertility: assisted reproductive technology has no adverse impact on pain or quality-oflife scores. Fertil Steril. 2016; 105:978-987 e4. I Article I PubMed

23. Dunselman GA, Vermeulen N, Becker C, Calhaz-Jorge C, D'Hooghe T, De Bie B, Heikinheimo O, Horne AW, Kiesel L, Nap A, Prentice A, Saridogan E, Soriano D and Nelen W. ESHRE guideline: management of women with endometriosis. Hum Reprod. 2014; 29:400-12. | $\underline{\text { Article | PubMed }}$

24. Fadhlaoui A, de la Joliniere J.B and Feki A. Encometriosis and infertility: how and when to treat? Frontiers Surg 1. 2014. | Article

25. Hwu YM, Wu FS, Li SH, Sun FJ, Lin MH and Lee RK. The impact of endometrioma and laparoscopic cystectomy on serum anti-Mullerian hormone levels. Reprod Biol Endocrinol. 2011; 9:80. | Article | PubMed Abstract | PubMed FullText

26. Crochet $\mathrm{P}$, Lathi RB, Dahan $\mathrm{MH}$, Ocampo J, Nutis $\mathrm{M}$ and Nezhat CR. 
Kralickova et al., Pathology Discovery 2017,

http://www.hoajonline.com/journals/pdf/2052-7896-5-3.pdf

Control-matched surgical evaluation of endometriosis progression after IVF: a retrospective cohort study. Minerva Ginecol. 2016; 68:481-6. | Article I PubMed

27. Rizk B, Turki R, Lotfy H, Ranganathan S, Zahed H, Freeman AR, Shilbayeh Z, Sassy M, Shalaby M and Malik R. Surgery for endometriosis-associated infertility: do we exaggerate the magnitude of effect? Facts Views Vis Obgyn. 2015; 7:109-18. | PubMed Abstract | PubMed FullText

28. Soriano D, Adler I, Bouaziz J, Zolti M, Eisenberg VH, Goldenberg M, Seidman DS and Elizur SE. Fertility outcome of laparoscopic treatment in patients with severe endometriosis and repeated in vitro fertilization failures. Fertil Steril. 2016; 106:1264-1269. | Article | PubMed

29. Hamdan M, Dunselman G, Li TC and Cheong Y. The impact of endometrioma on IVF/ICSI outcomes: a systematic review and metaanalysis. Hum Reprod Update. 2015; 21:809-25. | Article | PubMed

30. Mavrelos $D$ and Saridogan $E$. Treatment of endometriosis in women desiring fertility. J Obstet Gynaecol India. 2015; 65:11-6. | Article | $\underline{\text { PubMed Abstract | PubMed FullText }}$

\section{Citation:}

Kralickova M and Vetvicka V. Endometriosis and assisted reproduction. Pathol Discov. 2017; 5:3. http://dx.doi.org/10.7243/2052-7896-5-3 